Editor's Note: These short reviews of a recent paper in the Journal, written exclusively by graduate students or postdoctoral fellows, are intended to mimic the journal clubs that exist in your own departments or institutions. For more information on the format and purpose of the Journal Club, please see http://www.jneurosci.org/misc/ifa_features.shtml.

\title{
What Can Immediate-Early Gene Expression Tell Us about Spatial Memory Retrieval?
}

\author{
Kevin Bolding and Joseph Biedenkapp \\ Department of Psychology and Center for Neuroscience, University of Colorado at Boulder, Boulder, Colorado 80309 \\ Review of Gusev et al. (http://www.jneurosci.org/cgi/content/full/25/41/9384)
}

\section{Introduction}

Memory researchers have long been fascinated with what happens to memories with time. Historically, two theories have made different predictions about the involvement of the hippocampus (HC) in the retrieval of remote memories. Systems consolidation theory predicts a diminishing role of the $\mathrm{HC}$, whereas multiple memory trace theory (MTT) suggests a continued involvement, regardless of the age of the memory. Recently, activation patterns of immediate-early genes have been used to shed light on this issue (Frankland and Bontempi, 2005). In a recent article in The Journal of Neuroscience, Gusev et al. (2005) characterized the pattern of $\mathrm{HC}$ activation during the retrieval of recent or remote place memories acquired in the Morris water maze task using mRNA expression of the immediateearly gene Arc. The authors suggest that their results favor systems consolidation theory over MTT because they found a decrease in the magnitude and complexity of Arc expression in the $\mathrm{HC}$ as the memory aged.

The authors report a reduction in $A r c$ mRNA in the HC during the retrieval of a remote memory for the platform compared with a recent memory [Gusev et al. (2005), their Fig. 9 (http://www. jneurosci.org/cgi/content/full/25/41/9384/

Received Nov. 10, 2005; revised Jan. 11, 2006; accepted Jan. 11, 2006.

Correspondence should be addressed to Kevin Bolding at the above address. E-mail: boldingk@colorado.edu.

DOI:10.1523/JNEUROSCI.4848-05.2006

Copyright $\odot 2006$ Society for Neuroscience $\quad$ 0270-6474/06/261659-002\$15.00/0
FIG90]. The expression pattern differed across HC subregions. Arc mRNA decreased the most across the retention span in CA1 and in the ventral HC. Activity in $\mathrm{CA} 3$, the dorsal $\mathrm{HC}$, and the entorhinal cortex was more consistent across both recent and remote time points, although it still decreased somewhat. The authors conclude that this difference between subregions indicates a more persistent role for CA3 and dorsal HC neurons in the retrieval of water maze memory. By analyzing sections of the $\mathrm{HC}$ along the rostrocaudal axis, Gusev et al. detected clusters of activation within subregions in dorsal and ventral HC [Gusev et al. (2005), their Figs. 6 (http://www.jneurosci.org/cgi/ content/full/25/41/9384/FIG6), 7 (http:// www.jneurosci.org/cgi/content/full/25/ 41/9384/FIG7)]. These results suggest that subdivisions at a finer grain may play specific roles in spatial memory.

We appreciate the fine level of analysis this paper presents and the detailed description of the differential involvement of HC subregions in spatial memory retrieval across time. However, empirical, methodological, and conceptual issues constrain some of the interpretation. First, there is evidence suggesting that systems consolidation does not occur in the Morris water maze task (Sutherland et al., 2001; Clark et al., 2004; Martin et al., 2005). That is, hippocampus lesions always result in spatial memory impairment, regardless of the age of the memory. In addition, retention of the platform location reported by the authors was quite poor during both the recent and remote probe trials. Search time in the target quadrant is just above that predicted by chance, even at the recent time point, leaving one to wonder whether the rats really preferred this quadrant [Gusev et al. (2005), their Table 1 (http://www. jneurosci.org/cgi/content/full/25/41/9384/ TBL1)]. The authors attribute this to the fact that the rats were not trained to dwell near the platform, but rats with strong spatial memory can show selective search without this sort of training (Micheau et al., 2004). It is clear from the latency data during the first probe trial in the remote memory group that forgetting of some sort occurred, and the search time in the target quadrant appears to actually increase across probe trials. This argues against extinction but seems to indicate an active memory process. Given these behavioral issues, it is more difficult to interpret the meaning of the Arc activation during probe tests.

Immediate-early genes are used to map the brain regions involved in the retrieval of memories because it is assumed that retrieval produces activity at the synapses supporting the memory. This activity leads to a signal to the nucleus that drives the transcription of immediateearly genes. The authors measure the density of staining for Arc mRNA in regions of the hippocampus and conclude that because this activity marker decreases between recent and remote retrieval tests, the involvement of those regions in supporting the memory must also be decreas- 
ing over time. They suggest that this decrease provides evidence for systems consolidation but not MTT. However, we argue that standard densitometry cannot differentiate between these two competing theories. We believe this because (1) most plasticity researchers agree that the synapse is the basic unit of memory storage; (2) memory traces may be stored in multiple cells or on single cells via the involvement of multiple synapses; (3) densitometric analysis quantifies mRNA content throughout the cell rather than measuring a synapse-specific signal, so it cannot differentiate between the possibilities in (2).

For example, a decrease in the number of Arc-expressing cells could occur at the same time as an increase in the number of synapses (multiple memory traces) on the remaining "active" cells that support retrieval of the memory. In this case, al- though the absolute number of active cells may decrease, the brain region under examination is no less involved in the retrieval of the memory. A higher-resolution method focusing on mRNAs or proteins localized to active synapses is required to detect this type of reorganization.

In conclusion, Gusev et al. provide a detailed description of the pattern of Arc mRNA in the HC after recent and remote memory retrieval in the Morris water maze task. Although the issues discussed here limit the conclusions, the data stimulate conceptual questions about what the activation patterns in the brain can tell us about the involvement of those structures in memory retrieval.

\section{References}

Clark RE, Broadbent NJ, Squire LR (2005) Hippocampus and remote spatial memory in rats. Hippocampus 15:260-272.

Frankland PW, Bontempi B (2005) The organi- zation of recent and remote memories. Nat Rev Neurosci 6:119-130.

Gusev PA, Cui C, Alkon DL, Gubin AN (2005) Topography of Arc/Arg3.1 mRNA expression in the dorsal and ventral hippocampus induced by recent and remote spatial memory recall: dissociation of CA3 and CA1 activation. J Neurosci 25:9384-9397.

Martin SJ, de Hoz L, Morris RG (2005) Retrograde amnesia: neither partial nor complete hippocampal lesions in rats result in preferential sparing of remote spatial memory, even after reminding. Neuropsychologia 43:609-624.

Micheau J, Riedel G, Roloff EL, Inglis J, Morris RG (2004) Reversible hippocampal inactivation partially dissociates how and where to search in the water maze. Behav Neurosci 118:1022-1032.

Sutherland RJ, Weisend MP, Mumby D, Astur RS, Hanlon FM, Koerner A, Thomas MJ, Wu Y, Moses SN, Cole C, Hamilton DA, Hoesing JM (2001) Retrograde amnesia after hippocampal damage: recent vs. remote memories in two tasks. Hippocampus 11:27-42. 